\title{
Moderating Effect of Vigorous Physical Activity on Health Care Costs among Adolescents: ABCD Growth Study
}

\section{Lucas Gabriel Moraes Chagas ( $\sim$ lucas.chagas@unesp.br)}

Laboratory of InVestigation in Exercise - LIVE, Department of Physical Education, São Paulo State University (UNESP), Presidente Prudente, São Paulo

\section{Rômulo Araújo Fernandes}

Laboratory of InVestigation in Exercise - LIVE, Department of Physical Education, São Paulo State University (UNESP), Presidente Prudente, São Paulo

\section{Monique Yndawe Castanho Araujo}

Laboratory of InVestigation in Exercise - LIVE, Department of Physical Education, São Paulo State University (UNESP), Presidente Prudente, São Paulo

\section{Wésley Torres}

Laboratory of InVestigation in Exercise - LIVE, Department of Physical Education, São Paulo State University (UNESP), Presidente Prudente, São Paulo

\section{Jacqueline Bexiga Urban}

Laboratory of InVestigation in Exercise - LIVE, Department of Physical Education, São Paulo State University (UNESP), Presidente Prudente, São Paulo

\section{Santiago Maillane-Vanegas}

Laboratory of InVestigation in Exercise - LIVE, Department of Physical Education, São Paulo State University (UNESP), Presidente Prudente, São Paulo

\section{Bruna Camilo Turi-Lynch}

Lander University

\section{Jamile Sanches Codogno}

Laboratory of InVestigation in Exercise - LIVE, Department of Physical Education, São Paulo State University (UNESP), Presidente Prudente, São Paulo

\section{Nana Kwame Anokye}

Brunel University

\section{Research Article}

Keywords: Exercise, Pediatrics, Sedentary lifestyle, Drug costs, Health Economics.

Posted Date: August 18th, 2021 
DOI: https://doi.org/10.21203/rs.3.rs-691117/v1

License: (c) (1) This work is licensed under a Creative Commons Attribution 4.0 International License. Read Full License 


\section{Abstract}

Background: The relationship between physical activity and health care costs among adolescents is not yet clear in the literature.

Objective: To analyze the relationship between physical activity and annual health care costs among adolescents.

Methods: The present sample was composed of 85 adolescents of both sexes with ages ranging from 11

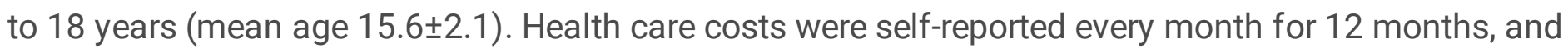
information on health care values was verified at local pharmacies, private health care plans, and the National Health Service. The time spent in different physical activity intensities was objectively measured by accelerometers. Confounding variables were: sex, age, somatic maturation, body fatness, blood pressure, and components of dyslipidemia and insulin resistance. Multivariate models were generated using generalized linear models with gamma distribution and a log-link function.

Results: The overall annual health care cost was US\$ 733.60/ R\$2,342.38 (medication: US\$ 400.46 / R\$ 1,278.66; primary and secondary care: US\$333.14 / R\$ 1,063.70). The time spent in vigorous physical activity (minutes/day) was negatively related to health care costs $(r=-0.342[95 \% \mathrm{Cl}:-0.537,-0.139] ; \beta=$ -0.06 cents ( $95 \% \mathrm{Cl}:-0.089,-0.031)$.

Conclusion: Vigorous physical activity seems to be associated with lower health care costs among adolescents.

\section{Introduction}

Over the last decades, significant lifestyle changes have occurred among pediatric groups moving toward increased time in sedentary behavior and less moderate-to-vigorous physical activity (MVPA) [1]. In terms of guidelines, the current recommendations for children and adolescents indicate that they should perform at least 60 minutes of MVPA daily [2]. Several health benefits are related to maintenance of adequate levels of physical activity, including improvements in cardiac and muscular outcomes $[3,4]$, as well as reduced risk of obesity [5].

Although the impact of physical activity on health benefits is well known, its potential impact on economic aspects remains unclear among pediatric groups. Among adults, data from 142 countries indicate that in 2013, physical inactivity was associated with US\$ 54 billion of health spending worldwide [6]. Evidence also suggests that a reduction of $10 \%$ in the prevalence of physical inactivity would result in a reduction in health care expenditures of US\$150 million per year [7].

Similarly, physical inactivity is also associated with muscle pain [8], a health outcome that tracks from adolescence to adulthood [9], generating a relevant economic burden among adults [10]. For instance, low back pain is a common event among adolescents, who commonly seek medical attention and use 
medications in order to treat it. However, little is known about the relationship of physical activity and musculoskeletal symptoms with health care costs in pediatric groups.

There are plausible reasons to believe that physical activity is able to mitigate health care costs, mainly because physical activity prevents the development of many diseases and aids avoidance of early mortality in adults $[11,12]$. However, among pediatric groups the issue is rarely investigated mainly due to the main determinants of health care costs -chronic diseases- [13] are less common in children and adolescents. On the other hand, due to rising rates of childhood obesity and musculoskeletal symptoms worldwide [14], there is a growing call for more evidence on the economic burden of these disorders among pediatric groups $[15,16]$.

Although maintenance of adequate levels of physical activity among pediatric groups has proven to be effective to avoid childhood obesity and many other diseases, there is a gap in the literature regarding its impact on health care costs. This is a pioneering study not only in Brazil but in the world, as few crosssectional studies have verified this relationship, and findings are conflicting $[17,18]$. Thus, the aim of the current study is to analyze the relationship between objectively measured physical activity and health care costs during one year among adolescents.

\section{Methods}

\section{Sample}

The cohort study entitled "Analysis of Behaviors of Children During Growth" (ABCD - Growth Study) has been ongoing in Presidente Prudente since 2017 ( 200,000 inhabitants and human development index 0.806; western state of São Paulo, Brazil). The data came from the 2018 round of the ABCD annual survey in Brazil, which collected objective measures of physical activity, to identify the impact of physical activity/sports participation on different health aspects of adolescents, including health care costs. The ethics committee of the São Paulo State University (UNESP) approved the study (process number 1.677.938/2016).

More details about the sampling process can be found elsewhere $[19,20]$. In brief, at baseline, researchers contacted adolescents in eleven school units and sports clubs spread out in the metropolitan region of the city. In the first contact with the adolescents, researchers explained all the aims and inclusion criteria of the cohort study and written consent forms were delivered to those ones who confirmed that they fulfilled all inclusion criteria. Inclusion criteria adopted were as follows: 1) 11-18 years old, 2) parents' consent form signed, 3 ) if contacted in any sports club, at least one year of training experience to characterize consistent engagement; 4) if contacted in any school unit, at least one year without regular practice of sport or exercise; 4) absence of orthopedic disease which limits physical activity.

In the second contact, researchers collected the signed written consent forms, and then, interviews to take place in the university facilities were scheduled by phone. Data collection was performed at the Laboratory of InVestigation in Exercise (LIVE) in 2017 (baseline) and 2018 (12-month follow-up). In 2018, 
measurements involved 193 adolescents whose health care costs were tracked from 2017 to 2018 . Objective measures of physical activity were available for 85 adolescents who agreed to wear the accelerometer and had no missing data (representing $44.1 \%$ of the entire sample; ages ranging from 11 to 17 years; 58 boys and 27 girls). The flow diagram of the study is presented on Fig. 1. Adolescents who wore the accelerometer $(n=85)$ and adolescents who did not $(n=108)$ were similar in terms chronological age ( $p$-value $=0.87)$, somatic maturation ( $p$-value $=0.62)$, birth weight $(p$-value $=0.52)$, LDL$\mathrm{C}(p$-value $=0.26), \mathrm{HDL}-\mathrm{C}(p$-value $=0.69), \mathrm{HOMA-IR}(p$-value $=0.06), \operatorname{SBP}(p$-value $=0.08), \mathrm{DBP}(p$-value $=$ $0.32)$, and RHR ( $p$-value $=0.89)$. Moreover, sex distribution was similar in both groups $(p$-value $=1.00)$.

The authors defined the relationship between physical activity and health care costs as the main analysis of the current work, and, therefore, the sample size calculation was based on measures of relationship, in this case correlation ( $r$ ), mainly because correlations are easy to interpret measures of effect-size [21]. The statistical equation adopted to estimate the sample size considered a statistical power of $80 \%$ and significance of $0.05(Z=1.96)$ [22]. Thus, our sample size of 85 adolescents was able to detect coefficients of correlation $\geq 0.30$, being less effective to detect significant relationships of small magnitude.

\section{Dependent Variable: Health Care Costs}

As there are no previously validated methods to assess health care costs among children and adolescents, our study adopted an approach previously established to assess this outcome in adults [23-25]. Participants received a log to register all health care events (e.g. medical consultations, hospitalizations, laboratory tests, buying medicines) were, after receiving appropriate training provided by the researchers to complete the logs. Researchers contacted the participants (adolescents and their parents/legal guardians) monthly by phone in to assess the data registered in the logs. The logs contained data about the use of medication (name and dosage), primary and secondary care (medical specialties [e.g. pediatrician, general practitioner, ophthalmologist, orthopedist, ear, nose and throat specialist, dermatologist, pulmonologist, emergency doctor, physical therapist, speech therapist, psychotherapist, occupational therapist, homeopath, and others], occurrence of hospitalizations, laboratory tests, and other occurrences [e.g. car accidents]). Moreover, the log requested data about the way the medical service had been paid (private health care plans, National Health Service, and out-ofpocket costs). The researchers collected the data registered in the logs and contacted pharmacies (when bought by the participant), private health care plans (when paid by the participant), and the National Health Service (when provided by the government) for 12 months to check the price of all health care services. The prices paid by the National Health Service were provided by the local authorities (Department of Health), while the prices paid by private health care plans were established through direct consultation with the plans. Regarding medicines bought by the participants in pharmacies, we generated a weighted average unit price considering three different pharmacies (price collected by three independent researchers). There was no occurrence of health care costs attributed to hospitalizations 
and surgeries in the current study (only primary care services were reported by the participants). Moreover, the health care costs of all 85 adolescents were assessed monthly with no missing data.

The prices were estimated in the Brazilian currency (Real [R\$]), and then converted into American dollars (US\$). The exchange rate used was the average quotation (R\$ versus US\$) of the 12 months of follow-up (from 2017 to 2018 [US\$ 1.00 is equal to R\$ 3.193]), which was provided by the Brazilian Federal Reserve [26]. In addition, the health care costs were updated by the inflation observed in 2019 and 2020 (accumulated until September) [26].

\section{Independent Variable: Objectively Measured Physical Activity}

Physical activity level and sleep were collected using an accelerometer (Polar V800; Polar, Kempele, Finland). The Polar V800 provides accurate data about physical activity when compared to other accelerometers [27]. However, data on epoch length, definition of non-wearing time, and cut-off points for counts are pre-fixed by the manufacturer and not available in the manual (and were not released even after requested by the authors) [28]. The Polar V800 is a sport watch with an internal tri-axial accelerometer that records wrist movements (dimensions of $37 \mathrm{~mm} \times 56 \mathrm{~mm} \times 12.7 \mathrm{~mm}$; weight of $79 \mathrm{~g}$ ) [27].

The participant wore the device for five consecutive week days. The first and last days were excluded and thus three valid weekdays were counted. The device is waterproof and provides data about sleeping time. Adolescents wore the accelerometer for the entire day, except during sports participation due to the risk of injuries (as requested by the coaches). For each day analyzed, the device discriminated: I) step count, II) sleep time, III) rest time (sleep and rest, lying down), IV) sitting time (sitting and other passive behaviors), V) light (standing activities, light intensity tasks), VI) moderate (walking and other moderate activities), and VII) vigorous intensity activities (jogging, running and other intense activities) [28]. The average time of the three valid weekdays was counted and adolescents were classified as sufficiently $(\geq 60$ minutes/day of moderate-to-vigorous [VI + VII] physical activity [MVPA]) or insufficiently active (<60 minutes/day of MVPA) [29].

\section{Confounders}

It was assumed that obesity, sex, age, birth weight, biological maturation, and cardiovascular and metabolic parameters could be potential correlates among adolescents. The majority of these variables are correlates of health care costs in adults [23-25], except biological maturation and birth weight. In a face-to-face interview, the adolescents reported sex and birth date (chronological age), and parents/legal guardians provided data about birth weight. Somatic maturation (age at peak of height velocity [PHV]) was estimated using anthropometric measures [30], while whole body fatness (in percentage [BF\%]) was 
assessed using a dual-energy x-ray absorptiometry (DXA) scanner (Lunar DPX-NT; General Electric Healthcare, Little Chalfont, Buckinghamshire, UK) with GE Medical System Lunar software (version 4.7).

The self-report of any musculoskeletal symptoms in nine body segments (neck, shoulder, upper back, low back, elbows, wrists/hands, hips/thighs, knees, and ankles/feet) in the previous week (before the face-toface interview) was assessed using the Nordic Musculoskeletal Questionnaire [32]. A continuous variable considering the number of positive answers was created (score ranging from 0 [no symptom reported] to 9 [symptoms reported in all body segments]).

Cardiovascular measures were taken three times after 10 minutes resting. Resting heart rate (RHR), and systolic (SBP) and diastolic blood pressure (DBP) were measured using electronic devices (Omron Healthcare, Inc., Intellisense, model HEM 742 INT, Bannockburn, Illinois, USA), validated for the pediatric population [31]. The blood samples are collected with the patient sitting comfortably in their own chair, with arm supported and elbow straight, $10 \mathrm{~mL}$ of fasting venous blood were collected from the elbow crease in the morning by a trained nurse. High-density lipoprotein [HDL-C], low-density lipoprotein [LDL-C], glucose and insulin were measured in order to calculate the homeostatic model assessment [HOMA-IR]), and a private laboratory was responsible for all laboratory procedures (this laboratory meets all quality standards established by the Brazilian Ministry of Health).

\section{Statistical analysis}

Continuous data are expressed as mean and $95 \%$ confidence interval $(95 \% \mathrm{Cl})$. Median, 25th percentile (P25th ) and 75th percentile (P75th ) were used because health care costs and physical activity showed non-normal distribution. Bivariate analyses used the Mann-Whitney test to compare health care costs with physical activity (sufficiently active versus insufficiently active). The Pearson correlation and its $95 \% \mathrm{Cl}$ were used to assess the crude relationship between health care costs and physical activity. Health care costs were converted into log-10 due to non-parametric distribution). Generalized linear models using gamma distribution with a log-link function ([GLM-Gamma], expressed as $\beta$ and its $95 \% \mathrm{Cl}$ ) were employed to examine the relationship between physical activity and healthcare costs, controlling for covariates (sex, age, somatic maturation, birth weight, body fatness, resting heart rate, low and high density lipoprotein, musculoskeletal symptoms, and systolic and diastolic blood pressure). Due to the non-parametric distribution of the health care costs, a general linear model conserving a Gamma error distribution with a log link (GLM-Gamma) was adopted as multivariate model, because it fits well for positive-only data with positively-skewed errors [33]. The GLM-Gamma model was run considering a hierarchical approach to insert covariates, as follows: Model-1 (crude); Model-2 (adjusted by general information [sex, age, biological maturation, birth weight, and adiposity]); Model-3 (Model-2 plus metabolic variables [LDL-C, HDL-C, and HOMA-IR]); Model-4 (Model-3 plus cardiovascular variables [SBP, DBP, and RHR] and musculoskeletal symptoms). Statistical significance was set at $p<0.05$ and all analyses were performed using BioEstat software (version 5.2 [BioEstat, Teffe, Brazil]).

\section{Results}


The sample was composed of 85 adolescents with ages ranging from 11 to 17 years (mean age of 15.6 $\pm 2.1)$ and predominately males $(68.2 \%[n=58]$ versus $31.8 \%[n=27]$, respectively; $p$-value $=0.01)$. The proportion of adolescents meeting the physical activity guidelines was similar between boys and girls $(40.9 \%[n=49]$ versus $34.6 \%[n=36]$, respectively; $p$-value $=0.78)$.

Considering the entire sample, overall annual health care costs were US\$733.60/ R\$ 2,342.38 (medication: US\$ 400.46 / R\$ 1,278.66; primary and secondary care: US\$333.14 / R\$ 1,063.70). For medication, 27 adolescents reported the use of 50 drugs ( 18 paid for by the National Health Service, 31 out-of-pocket, and 01 by a private health care plan). For primary and secondary care, 17 adolescents reported 19 medical consultations ( 10 paid for by the National Health Service, 02 out-of-pocket, and 07 by private health care plans), being $n=07$ general practitioner, $n=05$ orthopedist, $n=02$ pediatrician, $n=02$ dermatologist, $\mathrm{n}=01$ pulmonologist, $\mathrm{n}=01$ neurologist, and $\mathrm{n}=01$ cardiologist. Moreover, nine adolescents reported 10 tests ( 4 paid for by the National Health Service and 6 by private health care plans), being $n=05 X$-ray (chest, foot, and hand), $n=03$ ultrasound (hand, knee, and abdomen), $n=01$ blood test, and $n=01$ electrocardiogram.

Adolescents meeting the physical activity guidelines presented similar values of somatic maturation, body composition, blood pressure, and birth weight to those adolescents who did not meet the guidelines. On the other hand, the time in a sitting position was $14 \%$ lower among adolescents meeting the physical activity guidelines compared to those who did not (496.7 min/day [P25th -P75th : 426.1 to 531.1] versus $578.0 \mathrm{~min} /$ day [P25th -P75th : 494.1 to 637.8], respectively) (Table 1). 
Table 1

General characteristics of the adolescents according to the physical activity recommendations $(n=85)$.

\begin{tabular}{|c|c|c|}
\hline & $\begin{array}{l}\text { MVPA (<60min/day) } \\
(n=49)\end{array}$ & $\begin{array}{l}\text { MVPA ( } \geq 60 \mathrm{~min} / \text { day }) \\
(n=36)\end{array}$ \\
\hline Variables & Mean $(95 \% \mathrm{Cl})$ & Mean $(95 \% \mathrm{Cl})$ \\
\hline Boys / Girls & $33 / 16$ & $25 / 11$ \\
\hline Age (years) & 15.7 (15.1 to 16.2 ) & 15.6 (14.7 to 16.5$)$ \\
\hline Body weight (kg) & 62.5 (58.1 to 66.9$)$ & $66.4(60.6$ to 72.1$)$ \\
\hline Height (cm) & 169.2 (166.5 to 171.1$)$ & $170.9(167.2$ to 174.6$)$ \\
\hline PHV (years) & 1.9 (1.5 to 2.3$)$ & 2.1 (1.4 to 2.7 ) \\
\hline Birthweight (g) & 3234.5 (3084.9 to 3247.8 ) & 3227.8 (2978.4 to 3477.3$)$ \\
\hline $\mathrm{BF}(\%)$ & 21.6 (18.4 to 24.8$)$ & 22.5 (18.7 to 26.3 ) \\
\hline LDL-C (mg/dL) & 74.6 (68.2 to 81.1$)$ & 67.2 (61.7 to 72.6$)$ \\
\hline $\mathrm{HDL}-\mathrm{C}(\mathrm{mg} / \mathrm{dL})$ & $53.2(49.7$ to 56.7$)$ & 50.8 (47.2 to 54.5$)$ \\
\hline HOMA-IR & 2.1 (1.5 to 2.5$)$ & $1.9(1.5$ to 2.2$)$ \\
\hline $\mathrm{SBP}(\mathrm{mmHg})$ & 115.9 (112.7 to 119.2$)$ & 119.2 (114.2 to 124.2$)$ \\
\hline $\mathrm{DBP}(\mathrm{mmHg})$ & 64.5 (62.5 to 66.5$)$ & 66.1 (63.2 to 68.8$)$ \\
\hline \multirow[t]{2}{*}{ RHR (bpm) } & $75.2(72.3$ to 78.1$)$ & 73.6 (70.1 to 77.2$)$ \\
\hline & Median (P25th - P75th )* & Median (P25th - P75th )* \\
\hline Not wearing (min/day) & $17.3(0.0$ to 57.3$)$ & 7.1 (0.0 to 37.5$)$ \\
\hline Sitting position (min/day) & 578.0 (494.1 to 637.8$)$ & $496.7(426.1$ to 531.1$)$ \\
\hline Light PA (min/day) & 261.1 (226.3 to 303.5$)$ & 319.7 (269.1 to 379.1$)$ \\
\hline Moderate PA (min/day) & 33.7 (23.5 to 41.1$)$ & 69.8 (57.9 to 81.2 ) \\
\hline Vigorous PA (min/day) & 4.1 (1.3 to 7.1$)$ & 15.1 (6.7 to 23.3$)$ \\
\hline Sleeping time (min/day) & 401.7 (367 to 484.8$)$ & 461.3 (413.1 to 484.3$)$ \\
\hline MKS (score) & $1.0(0.0$ to 2.0$)$ & $1.0(0.0$ to 3.0$)$ \\
\hline \multicolumn{3}{|c|}{$\begin{array}{l}*=\text { variable expressed as median, percentile } 25 \text { th and percentile } 75 \text { th due to non-normal distribution } \\
\text { (comparisons performed using Mann-Whitney's test); MVPA = moderate-to-vigorous physical activity } \\
\text { PA = physical activity; } S D=\text { standard-deviation; } P H V=\text { peak of height velocity (somatic maturation); } \\
\text { BF = body fatness by DXA; SBP = systolic blood pressure; DBP = diastolic blood pressure; } R H R= \\
\text { resting heart rate; LDL-C = low-density lipoprotein; HDL-C = high-density lipoprotein; HOMA-IR = } \\
\text { Homeostatic model assessment; MKS = musculoskeletal symptoms. }\end{array}$} \\
\hline
\end{tabular}


Adolescents who reached the physical activity recommendations, when compared to those adolescents who did not, accumulated less health care costs for medication (Median $=$ US\$ 0.33 [P75th : 0.34] versus Median $=$ US\$ 0.33 [P75th : 8.63], respectively) and total health care costs (Median $=$ US\$ 1.01 [P75th : 1.02] versus Median = US\$1.02 [P75th : 17.45], respectively) (Fig. 2).

Considering all possible intensities of physical activity and its relationship with the health care costs over the previous year (Table 2), the time spent in vigorous physical activity was negatively related to health care costs with a small magnitude $(r=-0.342 ; 95 \% \mathrm{Cl}:-0.537,-0.139])$. 
Table 2

Relationship between health care costs, covariates and physical activity among adolescents $(n=85)$.

\section{Dependent variable: Overall health care costs (US\$)}

Pearson correlation

Independent variables

$r_{\text {crude }}(95 \% \mathrm{Cl})$

General

Sex (girl $=0 /$ boy $=1)$

$-0.017(-0.229$ to 0.197$)$

Age (years)

0.092 (-0.124 to 0.299)

PHV (years)

0.202 (-0.012 to 0.398$)$

Birthweight (g)

0.026 (-0.188 to 0.238$)$

BF (\%)

0.028 (-0.186 to 0.240$)$

LDL-C (mg/dL)

0.290 (0.082 to 0.474$)$

HDL-C (mg/dL)

$0.052(-0.163$ to 0.262$)$

HOMA-IR

-0.105 (-0.311 to 0.111$)$

SBP $(\mathrm{mmHg})$

-0.206 (-0.402 to 0.007$)$

DBP $(\mathrm{mmHg})$

$-0.246(-0.436$ to -0.035$)$

RHR (bpm)

0.081 (-0.134 to 0.289$)$

MKS (score)

-0.065 ( -0.274 to 0.150$)$

Accelerometer

Seating position ( $\mathrm{min} /$ day)

0.132 (-0.083 to 0.336$)$

Light PA (min/day)

0.146 (-0.069 to 0.348$)$

Moderate PA (min/day)

$-0.200(-0.396$ to 0.014$)$

Vigorous PA (min/day)

$-0.342(-0.517$ to -0.139$)$

Sleeping time ( $\mathrm{min} /$ day)

$-0.130(-0.334$ to 0.085$)$

$\mathrm{PA}=$ physical activity; $95 \% \mathrm{Cl}=95 \%$ confidence interval; $\mathrm{PHV}=$ peak of height velocity (somatic maturation); $\mathrm{BF}=$ body fatness by $\mathrm{DXA} ; \mathrm{SBP}=$ systolic blood pressure; $\mathrm{DBP}=$ diastolic blood pressure; $\mathrm{RHR}=$ resting heart rate; $\mathrm{LDL}-\mathrm{C}=$ low-density lipoprotein; $\mathrm{HDL}-\mathrm{C}=$ high-density lipoprotein; HOMA-IR = Homeostatic model assessment; MKS = musculoskeletal symptoms.

In the GLM-Gamma (Table 3), every increase of a single minute of vigorous physical activity was associated with a reduction of US\$ -0.06 cents $(95 \% \mathrm{Cl}$ : -0.089 to -0.031$)$ in total health care costs (R\$ -0.19 cents [ $95 \% \mathrm{Cl}:-0.28$ to -0.10$]$ ), independently of confounders. Among these adolescents, the LDL-C covariate presented a significant impact on the dependent variable $(\beta=0.015$ [95\% Cl: 0.001 to 0.029$])$. 
Page 12/21 
Table 3

Multivariate relationship between health care costs and physical activity among adolescents $(n=85)$.

\section{GLM - Gamma (dependent variable: overall health care costs [US\$])}

\begin{tabular}{|c|c|c|c|c|}
\hline & Model - 1 & Model - 2 & Model - 3 & Model - 4 \\
\hline $\begin{array}{l}\text { Independent } \\
\text { variable }\end{array}$ & $\left(\beta_{95 \% \mathrm{Cl}}\right)$ & $\left(\beta_{95 \% \mathrm{Cl}}\right)$ & $\left(\beta_{95 \% \mathrm{Cl}}\right)$ & $\left(\beta_{95 \% \mathrm{Cl}}\right)$ \\
\hline $\begin{array}{l}\text { Vigorous PA } \\
\text { (min/day) }\end{array}$ & $\begin{array}{l}-0.073(-0.097 \\
-0.048)\end{array}$ & $\begin{array}{l}-0.063(-0.089 ; \\
-0.036)\end{array}$ & $\begin{array}{l}-0.059(-0.087 ; \\
-0.031)\end{array}$ & $\begin{array}{l}-0.060(-0.089 ; \\
-0.031)\end{array}$ \\
\hline \multicolumn{5}{|l|}{ Cofounders } \\
\hline $\begin{array}{l}\text { Sex (girl = } 0 / \text { boy } \\
=1)\end{array}$ & & $\begin{array}{l}0.001(-0.773 \\
0.774)\end{array}$ & $\begin{array}{l}-0.393(-1.322 \\
0.536)\end{array}$ & $\begin{array}{l}-0.492(-1.667 \\
0.683)\end{array}$ \\
\hline Age (years) & & $\begin{array}{l}-0.492(-0.907 ; \\
-0.077)\end{array}$ & $\begin{array}{l}-0.296(-0.752 ; \\
0.160)\end{array}$ & $\begin{array}{l}-0.318(-0.774 ; \\
0.139)\end{array}$ \\
\hline PHV (years) & & $\begin{array}{l}0.695(0.175 \\
1.214)\end{array}$ & $\begin{array}{l}0.400(-0.185 \\
0.984)\end{array}$ & $\begin{array}{l}0.372(-0.273 \\
1.016)\end{array}$ \\
\hline Birthweight (kg) & & $\begin{array}{l}-0.159(-0.547 \\
0.229)\end{array}$ & $\begin{array}{l}-0.012(-0.479 \\
0.455)\end{array}$ & $\begin{array}{l}-0.079(-0.562 \\
0.405)\end{array}$ \\
\hline $\mathrm{BF}(\%)$ & & $\begin{array}{l}-0.015(-0.044 \\
0.015)\end{array}$ & $\begin{array}{l}-0.024(-0.061 \\
0.13)\end{array}$ & $\begin{array}{l}-0.029(-0.072 \\
0.015)\end{array}$ \\
\hline LDL-C (mg/dL) & & & $\begin{array}{l}0.014(0.001 \\
0.028)\end{array}$ & $\begin{array}{l}0.015(0.001 ; \\
0.029)\end{array}$ \\
\hline $\mathrm{HDL}-\mathrm{C}(\mathrm{mg} / \mathrm{dL})$ & & & $\begin{array}{l}-0.012(-0.039 \\
0.014)\end{array}$ & $\begin{array}{l}-0.015(-0.044 \\
0.014)\end{array}$ \\
\hline HOMA-IR & & & $\begin{array}{l}0.030(-0.209 \\
0.270)\end{array}$ & $\begin{array}{l}0.053(-0.229 \\
0.335)\end{array}$ \\
\hline $\mathrm{SBP}(\mathrm{mmHg})$ & & & & $\begin{array}{l}0.010(-0.018 \\
0.037)\end{array}$ \\
\hline $\mathrm{DBP}(\mathrm{mmHg})$ & & & & $\begin{array}{l}0.305(-0.692 ; \\
1.305)\end{array}$ \\
\hline RHR (bpm) & & & & $\begin{array}{l}-1.369(-3.825 \\
1.101)\end{array}$ \\
\hline MKS (score) & & & & $\begin{array}{l}0.004(-0.169 \\
0.177)\end{array}$ \\
\hline
\end{tabular}




\section{Discussion}

In the current study, adolescents who met the general recommendations for physical activity accumulated less health care costs during 12 months of follow-up compared to those one who did not, mainly due to the time spent in vigorous activities.

The results showed that physical activity and health care costs were inversely related. This theme is surrounded by uncertainty in the pediatric literature (e.g. the existence of the relationship and even its direction), mainly because although this research topic has received growing attention recently, the focus has been on adults.[6] A previous German survey evaluated more than 3,000 children aged 9 to 12 years and failed to find a significant relationship between physical activity and health care costs [18], concluding that the moment of childhood is an early stage to determine significant effects of physical activity on health expenditures.

On the other hand, differences in methodology might justify these divergences from the literature. First, in our study, health care costs attributed to medication were more prone to be mitigated by physical activity. Medication accounted for $54.5 \%$ of all health care costs in our sample, while the study by Idler et al. [34] counted health care costs for primary and secondary care but not medication. Similarly, the inverse relationship between physical activity (number of steps) and costs attributed to medicine has also been identified in 40-65 year-old adults [35].

Second, the way in which physical activity was assessed in both studies deserves to be highlighted. In the German study, physical activity was self-reported using a questionnaire [18, 34][34], while in our study physical activity was assessed using an objective measurement method (accelerometers). This technical issue seems more relevant to support the differences between both studies because only vigorous physical activity was inversely related to economic variables. In fact, although questionnaires are useful in large surveys, they usually fail to precisely record the time spent in different physical activity intensities [36]. Therefore, if the main pathway linking physical activity and health care costs in adolescents is the intensity, the limitation of questionnaires becomes critically relevant.

Initially, it was supposed that obesity would be the main factor supporting an inverse relationship between physical activity and health care costs among these adolescents $[15,16]$. However, our findings refuted that hypothesis, in which higher values of LDL-C assumed a relevant role as a determinant of health care costs, independently of physical activity. First, the independence between both is justified because as mentioned above, physical activity seems particularly related to health care costs attributed to medication, while LDL-C values were related to health care costs attributed to primary and secondary care $(r=0.291$; $p$-value $=0.009)$. In fact, dyslipidemia is a health outcome with growing prevalence among adolescents (reaching $61 \%$ depending on the cut point adopted) [37] and, naturally, leading to a higher number of medical consultations in order to treat it. Moreover, even assuming that alterations in LDL-C concentration are strongly affected by obesity, this is not mandatory, because dyslipidemia also occurs in children and adolescents with normal weight but with poor diet habits [38]. 
In terms of limitations, it is necessary to recognize some in our study. First, although all health care costs were counted over a 12-month period, physical activity was measured from a cross-sectional perspective (only in the follow-up moment). Therefore, it is desirable that future studies try to identify the impact of changes in physical activity on health care costs. Second, even considering that health care costs were self-reported every single month, it is necessary to consider the presence of recall bias in the information reported by parents and adolescents, leading to possible underestimation of the real monetary values. Third, the small sample size is a limitation in this study due to obvious issues related to the generalization of the findings. In adults, physical activity intensity and health care costs from primary care are significantly related to each other [39], but in a smaller magnitude $(r=-0.22)$ than our sample size was able to detect $(r=-0.30)$. The fact our sample size was small might have affected its ability to detect the relationship between health care costs and other domains of physical activity intensity (e.g. light and moderate). Therefore, while vigorous physical activity should be recommended for pediatric groups in order to promote health and mitigation of health care costs [40], other activities requiring less energy expenditure should also be recommended. Finally, data on epoch length, definition of non-wearing time, and cut-off points for counts were pre-fixed by the manufacturer and were not available to the research team. The absence of these data is relevant because it limits comparisons with previous studies using accelerometers (due to the number of cut-points adopted in the literature).

\section{Conclusion}

Our findings suggest that only vigorous physical activity seems to be associated with lower health care costs among adolescents, denoting the relevance of the regular engagement of adolescents in activities of higher physical demand. Our findings highlight the significant potential attributed to physical activity to mitigate health care costs from an early age. Thus, it is important to highlight the need for research in this area, aiming to improve actions in public health, promoting healthier lifestyles through physical activities among children and adolescents. This could be a powerful tool for reducing health risk factors, such as obesity, and minimizing health care spending.

\section{Abbreviations}

MVPA: moderate-to-vigorous physical activity; ABCD - Growth Study: Analysis of Behaviors of Children During Growth; UNESP: São Paulo State University; LIVE: Laboratory of InVestigation in Exercise; LDL-C: low-density lipoprotein; HDL-C: high-density lipoprotein; HOMA-IR: homeostatic model assessment of insulin resistance; SBP: systolic blood pressure; DBP: diastolic blood pressure; RHR: resting heart rate; PHV: peak height velocity; BF: body fatness; DXA: dual-energy x-ray absorptiometry.

\section{Declarations}

\section{Ethics approval and consent to participate}


The study was approved by the Ethics Research Committee of the Sao Paulo State University (process number: 1.677.938/2016 and Process number 02891112.6.0000.5402), Campus of Presidente Prudente. Informed consent was obtained in writing from all individual participants included in the study and their parents or legal guardians.

\section{Consent for publication}

Not applicable

\section{Availability of data and materials}

The data collected and analyzed during this study are stored by the authors upon authorization by the leader of the Laboratory of InVestigation in Exercise (LIVE) which involves the ABCD Growth Study.

\section{Competing interests}

The authors declare that they have no competing interests.

\section{Funding}

The ABCD Growth Study was supported in part by CNPq (Conselho Nacional de Desenvolvimento Científico e Tecnológico), CAPES (Coordenação de Aperfeiçoamento de Pessoal de Nível Superior - Brasil - Finance Code 001) and São Paulo Research Foundation (FAPESP RAF (Process: 2018/22593-7) and LGMC(Process: 2018/11839-5)).

\section{Authors' contributions}

LGMC and RAF were responsible for the study concept, design and ethics applications. MYCA, WT, JAB, SMV were involved in the conception, data collection, made substantial contributions to analysis and interpretation of data and revising it critically for important intellectual content; BCTL, JSC and NKA were made substantial contributions to conception and acquisition of data and analysis and interpretation of data and was involved in revising it critically for important intellectual content.

Acknowledgements: The authors would like to thank to all volunteers who agreed to participate in this research, and all members of the Scientific Research Group Related to Physical Activity (GICRAF) UNESP/ Brazil who helped with the sampling and logistics of the data collection.

\section{References}

1. Ng SW, Popkin BM. Time use and physical activity: A shift away from movement across the globe. Obesity Reviews. 2012.

2. World Health Organization. Global Recommendations on Physical Activity for Health WHO Library Cataloguing-in-Publication Data Global recommendations on physical activity for health. 2010. 
3. Henje Blom E, Olsson EMG, Serlachius E, Ericson M, Ingvar M. Heart rate variability is related to selfreported physical activity in a healthy adolescent population. European Journal of Applied Physiology. 2009.

4. Alves JGB, Alves GV. Effects of physical activity on children's growth. Jornal de Pediatria. 2019;95:728.

5. Berkey CS, Rockett HRH, Field AE, Gillman MW, Frazier AL, Camargo CA, et al. Activity, Dietary Intake, and Weight Changes in a Longitudinal Study of Preadolescent and Adolescent Boys and Girls. Pediatrics. 2000.

6. Ding D, Lawson KD, Kolbe-Alexander TL, Finkelstein EA, Katzmarzyk PT, van Mechelen W, et al. The economic burden of physical inactivity: a global analysis of major non-communicable diseases. The Lancet. 2016.

7. Katzmarzyk PT, Gledhill N, Shephard RJ. The economic burden of physical inactivity in Canada. CMAJ: Canadian Medical Association journal = journal de l'Association medicale canadienne. 2000;163:143540. http://www.ncbi.nlm.nih.gov/pubmed/11192648.

8. Scarabottolo CC, Pinto RZ, Oliveira CB, Zanuto EF, Cardoso JR, Christofaro DGD. Back and neck pain prevalence and their association with physical inactivity domains in adolescents. European Spine Journal. 2017;26:2274-80.

9. Kamper SJ, Henschke N, Hestbaek L, Dunn KM, Williams CM. Musculoskeletal pain in children and adolescents. Braz J Phys Ther.

10. Holth HS, Werpen HKB, Zwart JA, Hagen K. Physical inactivity is associated with chronic musculoskeletal complaints 11 years later: Results from the Nord-Trøndelag Health Study. BMC Musculoskeletal Disorders. 2008;9:159.

11. Fernandes RA, Zanesco A. Early sport practice is related to lower prevalence of cardiovascular and metabolic outcomes in adults independently of overweight and current physical activity. Medicina (Kaunas, Lithuania). 2015;51:336-42. doi:10.1016/j.medici.2015.10.003.

12. Turi BC, Monteiro HL, Lemes R, Codogno JS, Lynch KR, Asahi Mesquita CA, et al. TV viewing time is associated with increased all-cause mortality in Brazilian adults independent of physical activity. Scandinavian Journal of Medicine and Science in Sports. 2018.

13. Turi BC, Codogno JS, Fernandes RA, Lynch KR, Kokubun E, Monteiro HL. Time trends in physical activity of adult users of the Brazilian National Health System: 2010-2014. Longitudinal study. Sao Paulo Medical Journal. 2017.

14. Bentham J, Di Cesare M, Bilano V, Bixby H, Zhou B, Stevens GA, et al. Worldwide trends in body-mass index, underweight, overweight, and obesity from 1975 to 2016: a pooled analysis of 2416 population- 
based measurement studies in 128.9 million children, adolescents, and adults. The Lancet. 2017;390:2627-42.

15. Wang G, Dietz WH. Economic Burden of Obesity in Youths Aged 6 to 17 Years: 1979-1999. PEDIATRICS. 2002.

16. HampI SE, Carroll CA, Simon SD, Sharma V. Resource utilization and expenditures for overweight and obese children. Archives of Pediatrics and Adolescent Medicine. 2007.

17. Kirk SFL, Kuhle S, Ohinmaa A, Veugelers PJ. Health behaviours and health-care utilization in Canadian schoolchildren. Public health nutrition. 2013;16:358-64.

18. Idler N, Teuner CM, Hunger M, Holle R, Ortlieb S, Schulz $\mathrm{H}$, et al. The association between physical activity and healthcare costs in children. BMC public health. 2015;15:437.

19. Cayres SU, Werneck AO, Urban JB, Turi-Lynch BC, Barbosa MF, Fernandes RA. Sports participation is inversely associated with C-reactive protein levels in adolescents: ABCD Growth Study. Scandinavian Journal of Medicine and Science in Sports. 2019.

20. Werneck AO, Agostinete RR, Cayres SU, Urban JB, Wigna A, Chagas LG de M, et al. Association between Cluster of Lifestyle Behaviors and HOMA-IR among Adolescents: ABCD Growth Study. Medicina (Kaunas, Lithuania). 2018;54:96. doi:10.3390/medicina54060096.

21. Maher JM, Markey JC, Ebert-May D. The other half of the story: Effect size analysis in quantitative research. CBE Life Sciences Education. 2013;12:345-51.

22. Miot HA. Sample size in clinical and experimental. Jornal Vascular Brasileiro. 2011;10:275-8.

23. Codogno JS, Fernandes RA, Sarti FM, Freitas Júnior IF, Monteiro HL. The burden of physical activity on type 2 diabetes public healthcare expenditures among adults: A retrospective study. BMC Public Health. 2011.

24. Araujo MYC, Sarti FM, Fernandes RA, Monteiro HL, Turi BC, Anokye N, et al. Association between Costs Related to Productivity Loss and Modified Risk Factors among Users of the Brazilian National Health System. Journal of Occupational and Environmental Medicine. 2017.

25. Codogno JS, Turi BC, Kemper HCG, Fernandes RA, Christofaro DGD, Monteiro HL. Physical inactivity of adults and 1-year health care expenditures in Brazil. International Journal of Public Health. 2015.

26. Banco Central do Brasil. https://www.bcb.gov.br/. Accessed 6 Jul 2021.

27. Hernández-Vicente A, Santos-Lozano A, De Cocker K, Garatachea N. Validation study of Polar V800 accelerometer. Annals of Translational Medicine. 2016;4:278-278. doi:10.21037/atm.2016.07.16. 
29. Silva DAS, Christofaro DGD, Ferrari GL de M, da Silva KS, Nardo N, Dos Santos Silva RJ, et al. Results From Brazil's 2018 Report Card on Physical Activity for Children and Youth. Journal of physical activity \& health. 2018;15:S323-5.

30. Mirwald RL, Baxter-Jones ADG, Bailey DA, Beunen GP. An assessment of maturity from anthropometric measurements. Medicine and science in sports and exercise. 2002;34:689-94. doi:10.1097/00005768-200204000-00020.

31. Christofaro DGD, Fernandes RA, Gerage AM, Alves MJ, Polito MD, Oliveira AR de. Validation of the Omron HEM 742 blood pressure monitoring device in adolescents. Arquivos brasileiros de cardiologia. 2009;92:10-5. doi:10.1590/s0066-782×2009000100003.

32. de Barros ENC, Alexandre NMC. Cross-cultural adaptation of the Nordic musculoskeletal questionnaire. International nursing review. 2003;50:101-8. doi:10.1046/j.1466-7657.2003.00188.x.

33. Aalabaf-Sabaghi M. Decision modelling for health economic evaluation. Journal of Epidemiology \&amp; Community Health. 2007;61:839-839.

34. Idler N, Teuner CM, Hunger M, Holle R, Ortlieb S, Schulz H, et al. The association between physical activity and healthcare costs in children - Results from the GINIplus and LISAplus cohort studies Health behavior, health promotion and society. BMC Public Health. 2015.

35. Fernandes RA, Mantovani AM, Codogno JS, Turi-Lynch BC, Pokhrel S, Anokye N. The Relationship between Lifestyle and Costs Related to Medicine Use in Adults. Arquivos brasileiros de cardiologia. 2019;112:749-55. doi:10.5935/abc.20190049.

36. Ndahimana D, Kim E-K. Measurement Methods for Physical Activity and Energy Expenditure: a Review. Clinical nutrition research. 2017;6:68-80. doi:10.7762/cnr.2017.6.2.68.

37. Tomeleri CM, Ronque ERV, Silva DRP, Cardoso Júnior CG, Fernandes RA, Teixeira DC, et al. Prevalence of dyslipidemia in adolescents: Comparison between definitions. Revista Portuguesa de Cardiologia. 2015;34:103-9. doi:10.1016/j.repc.2014.08.020.

38. Dahm CC, Chomistek AK, Jakobsen MU, Mukamal KJ, Eliassen AH, Sesso HD, et al. Adolescent Diet Quality and Cardiovascular Disease Risk Factors and Incident Cardiovascular Disease in Middle-Aged Women. Journal of the American Heart Association. 2016.

39. Codogno JS, Monteiro HL, Turi-Lynch BC, Fernandes RA, Pokhrel S, Anokye N. Sports Participation and Health Care Costs in Older Adults Aged 50 Years or Older. Journal of Aging and Physical Activity. 2020;28:634-40.

40. Fernandes RA, Zanesco A. Early physical activity promotes lower prevalence of chronic diseases in adulthood. Hypertension Research. 2010;33:926-31. 
Figures

\section{Data collection in 2018}

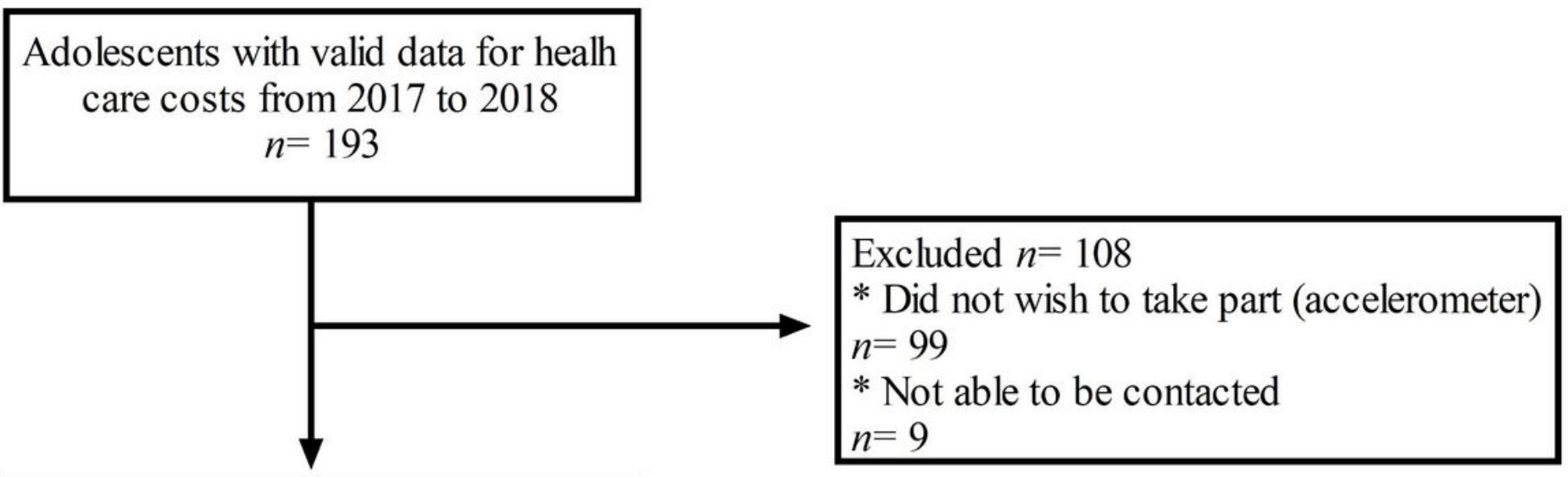

Adolescents with valid data for physical activity in 2018 and healh care costs from 2017 to 2018

$$
n=85
$$

Figure 1

Objective measures of physical activity were available for 85 adolescents who agreed to wear the accelerometer and had no missing data (representing $44.1 \%$ of the entire sample; ages ranging from 11 to 17 years; 58 boys and 27 girls). The flow diagram of the study is presented on Figure 1. 


\section{Health care cost accumulated over 12-months (US\$)}

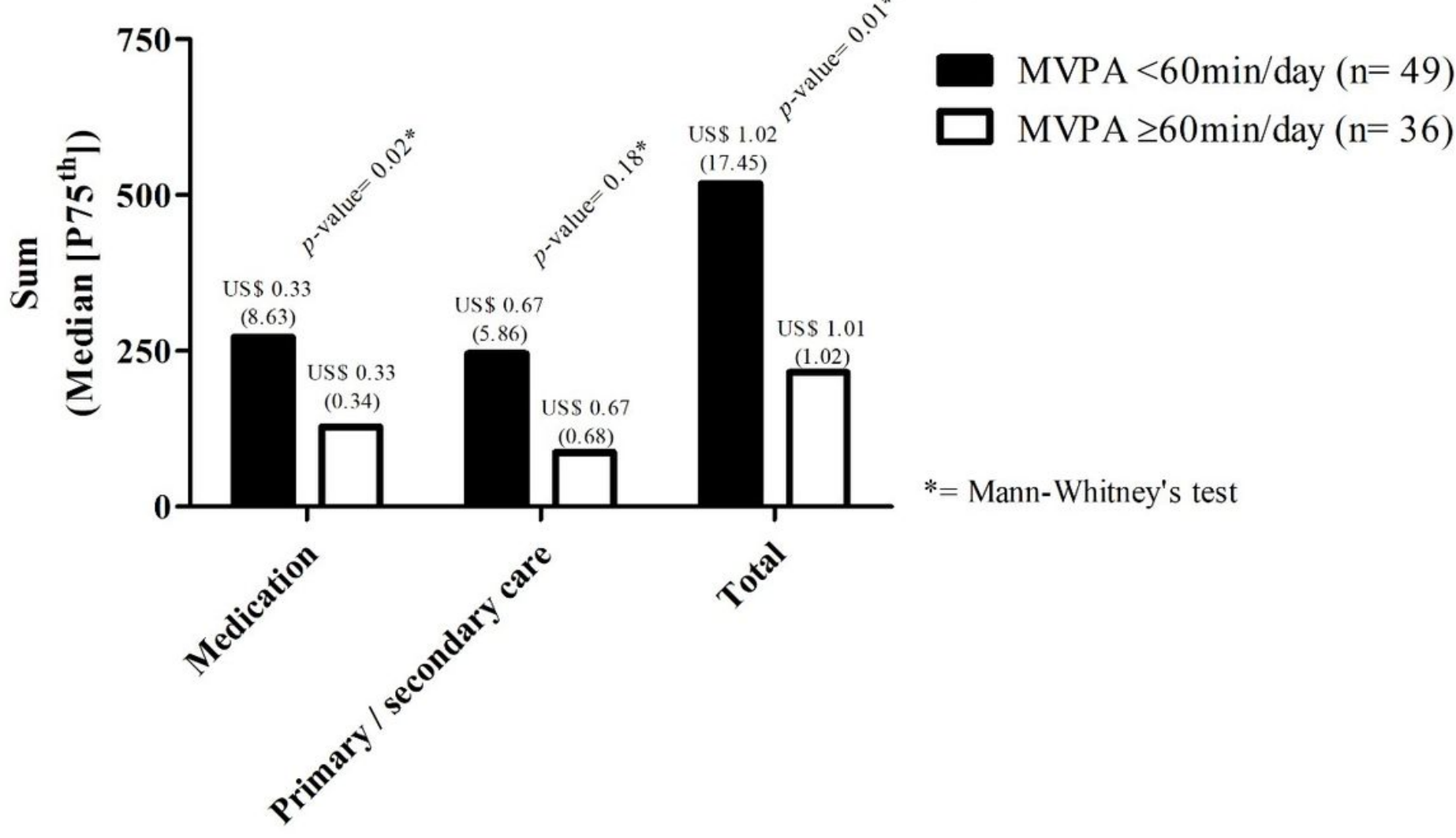

Subsets of health care costs

Figure 2

Adolescents who reached the physical activity recommendations, when compared to those adolescents who did not, accumulated less health care costs for medication (Median= US\$ 0.33 [P75th: 0.34] versus Median= US\$ 0.33 [P75th: 8.63], respectively) and total health care costs (Median= US\$ 1.01 [P75th: 1.02] versus Median= US\$ 1.02 [P75th: 17.45], respectively) (Figure 2). 